\title{
PHYSICS-BASED FIRE FOLLOWING EARTHQUAKE SIMULATION CONSIDERING BUILDING SEISMIC DAMAGE
}

\author{
Xiang Zeng ${ }^{1}$, Xinzheng $\mathrm{Lu}^{2}$, Zhen $\mathrm{Xu}^{3}$, and Qingle Cheng ${ }^{1}$ \\ ${ }^{1}$ Beijing Engineering Research Center of Steel and Concrete Composite Structures, Department of \\ Civil Engineering, Tsinghua University \\ Beijing 100084, P.R. China \\ cengx13@mails.tsinghua.eud.cn, chengq116@mails.tsinghua.edu.cn
}
${ }^{2}$ Key Laboratory of Civil Engineering Safety and Durability of China Education Ministry, Department of Civil Engineering, Tsinghua University
Beijing 100084, P.R. China
luxz@tsinghua.edu.cn
${ }^{3}$ School of Civil and Resource Engineering, University of Science and Technology Beijing
Beijing 100084, P.R. China
xuzhen@ustb.edu.cn

Keywords: Seismic damage simulation of urban region, Fire following earthquake, Ignition, Fire spread.

\begin{abstract}
Earthquakes may induce severe fire disasters in urban regions. Burnt buildings may have to be demolished, even if they have merely slight seismic damage, which will dramatically increase the recovery time of communities to regain their functionality. As a result, a rational fire following earthquake (FFE) simulation is important for the resilience assessment of communities after an earthquake. This work proposes a framework for the physicsbased simulation of FFE considering building seismic damage, through which the accuracy, rationality and usability of FFE simulation are improved. Specifically, the seismic damage of regional buildings is simulated using multiple degree-of-freedom (MDOF) building models and nonlinear time-history analysis. A case study of the FFE simulation of downtown Tangshan City with 230,683 buildings is performed. The results show that the influence of different ground motions and building seismic resistances on fire ignition and fire spread can be taken into account with the proposed method. The proposed FFE simulation method can serve as important technical supports for FFE prevention and disaster management.
\end{abstract}




\section{INTRODUCTION}

Earthquakes may cause severe fire problems. For example, in the 1906 San Francisco earthquake, the building damage due to fire following earthquake (FFE) accounted for $80 \%$ of the total damage [1], i.e., the losses caused by FFE was four times of the direct earthquake losses. Moreover, burnt buildings have to be demolished, even if they have merely slight seismic damage, which will dramatically increase the recovery time of communities to regain their functionality. As a result, a rational FFE simulation is important for the resilience assessment of communities after an earthquake.

The existing FFE models are mainly categorized into two types: (1) ignition models, which simulate the number of ignited buildings in a given zone under a certain seismic intensity; and (2) fire spread models, which simulate the fire development in an individual building and among neighborhood buildings.

Most of the ignition models [2] use the regression methods to determine the relationship between the ignition rate and seismic intensity measures, based on the statistics of historical FFE events. Generally, the regression models only provide the number of ignited buildings at a given seismic intensity. However, the exact ignition locations are determined randomly or arbitrarily assigned by users.

Fire spread models have a tendency towards being physics-based rather than strictly empirical [2]. However, only a limited number of fire spread models consider the influence of building seismic damage on fire spread. The model proposed by Himoto et al. [3] made a remarkable progress with respect to these effects. Nevertheless, the seismic damage of buildings was randomly assigned in the case study of Himoto et al. [3] and there were no further discussions as how to simulate the building seismic damage in urban regions.

Remarkable progress has been achieved in developing a novel seismic damage simulation method for regional buildings in recent years [4-6]. Using multiple degree-of-freedom (MDOF) models in conjunction with nonlinear time-history analysis (THA), the dynamic seismic responses of a number of buildings can be obtained in an efficient and accurate way, which has the potential to further improve the capacity of the FFE models. Specifically, the influence of building seismic damage on fire ignition and spread can be considered more reasonably. Therefore, in this work, a framework for the FFE simulation, considering building seismic damage, is proposed based on the existing models of [4-6]. A case study of the FFE simulation of downtown Tangshan City with 230,683 buildings is performed. The results show that the influence of building seismic damage on fire spread can be reliably considered. The proposed FFE simulation method can provide important technical support for FFE prevention.

\section{FRAMEWORK}

The proposed framework consists of three parts (Figure 1): (1) seismic damage simulation of regional buildings; (2) ignition model; and (3) fire spread model. 


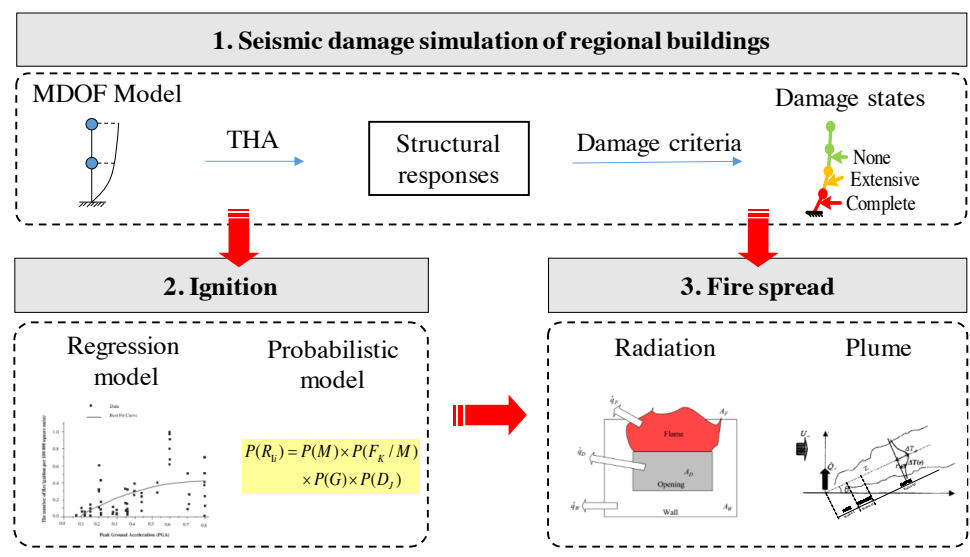

Figure 1: Framework of the FFE simulation.

\subsection{Seismic damage simulation of regional buildings}

Seismic damage simulation of regional buildings forms the basis of the subsequent FFE simulation. Generally, there are thousands of buildings in an urban region. To obtain an accurate and efficient seismic damage simulation of regional buildings, Xiong et al. [5, 6] performed a series of studies in which the low- and mid-rise buildings were simulated using the nonlinear MDOF shear models and the tall buildings were simulated using the nonlinear MDOF flexural-shear models. Using such models, the inter-story backbone curves and hysteretic parameters of the MDOF models can be determined based on the basic building GIS information (i.e., planar area, number of stories, building height, construction period, occupation and structural type) [5,6]. As a result, the nonlinear MDOF model of buildings can be automatically established. After that, the nonlinear THA is performed to calculate the seismic responses and damage of the buildings. The nonlinear THA of a number of buildings can be greatly accelerated through graphics processing unit (GPU)-powered parallel computing $[4,6]$. Xiong et al. $[5,6]$ validated the rationality and accuracy of these methods via plenty of case studies.

\subsection{Ignition model}

In most of the existing ignition models, the locations of ignition are determined randomly or arbitrarily assigned by the users. To determine the ignition locations more reasonably, Ren and Xie [7] proposed the following methodology: (1) calculate the number of ignited buildings $N$ using the regression model, given a seismic intensity; (2) calculate the igniting probability of each building using the probabilistic model of individual buildings; (3) sort the building igniting probability in a descending order; and (4) assign the top $N$ buildings with the highest igniting probability as the ignited buildings.

Since the regression models rely on the statistical data, a regression model generally performs better when applied to the regions where the historical FFE records are included in the statistics. As the case study presented in this work is a Chinese city, the model proposed by Ren and Xie [7], which uses the statistical data of historical FFE events in China, the United States, and Japan during 1900-1996, is therefore adopted in this work, as shown in Eq. (1):

$$
N=-0.11749+1.34534 P G A-0.8476 P G A^{2}
$$

where $N$ is the number of ignited buildings per 1 million $\mathrm{m}^{2}$ building area. The unit of peak ground acceleration $(P G A)$ is $\mathrm{g}$. 
Given a $P G A$, the igniting probability of an individual building $P(R \mid P G A)$ can be calculated using Eqs. (2) and (3) [7]:

$$
\begin{gathered}
P(R \mid P G A)=P(M) \times P\left(F_{K} \mid M\right) \times P(D \mid P G A) \times P(G) \\
P(D \mid P G A)=\sum_{j}\left[P\left(D_{j} \mid P G A\right) \times P\left(C_{j} \mid D_{j}\right) \times P\left(S_{j} \mid D_{j}\right)\right]
\end{gathered}
$$

where $P(D \mid P G A)$ represents the influence of building seismic damage on the igniting probability, given a $P G A$. The meanings and values of other parameters are listed in Table 1 .

Note that the igniting probability given by Eq. (2) may overestimate the ignition risk (i.e., the expected number of ignited buildings predicted by Eq. (2) will be greater than the number of buildings given by Eq. (1)). As a result, $P(R \mid P G A)$ should be treated as a measurement of relative ignition risk of different buildings instead of an absolute ignition risk. To emphasize this point and to avoid misleading, a new index, i.e., the building ignition risk $r$, is defined herein as:

$$
r=\frac{P(R \mid P G A)}{P(R)_{\max }} \times 100 \%
$$

where $P(R)_{\max }=0.867$ is the maximum value of Eqs. (2) and (3), under the condition that the building collapses due to an earthquake, the building contains flammable and explosive chemical material, and the weather conditions are unfavorable [7].

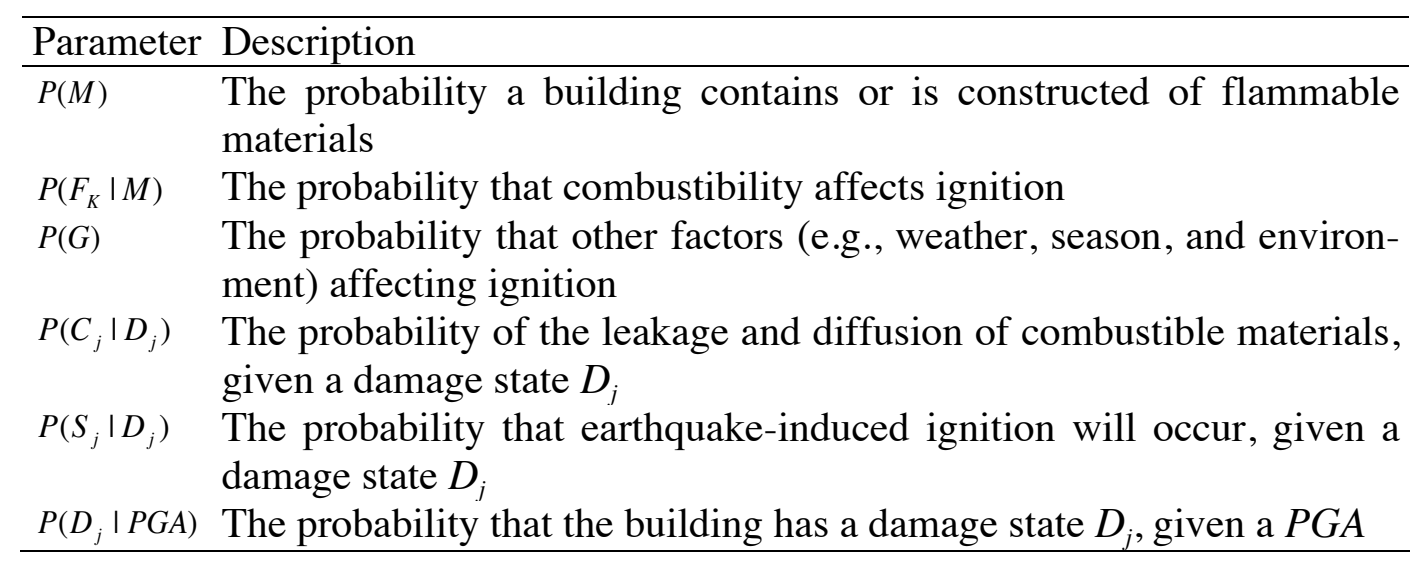

Table 1: Descriptions of the parameters in the equations of the probabilistic model.

Ren and Xie [7] provided the values of most parameters listed in Table 1, but they did not mention how to calculate $P\left(D_{j} \mid P G A\right)$. Some studies suggested using damage probability matrices to calculate $P\left(D_{j} \mid P G A\right)$ [8]. However, the damage probability matrices cannot identify the influence of different ground motion characteristics (e.g., with or without velocity pulse). Moreover, for the regions lacking historical seismic damage data, the accuracy of damage probability matrices should be carefully considered [6]. For this reason, the seismic damage simulation of regional buildings proposed by Xiong et al. [5, 6] is used in this study to calculate the probability of buildings experiencing different damage states 


\subsection{Fire spread model}

Fire spread consists of fire development in an individual building and fire spread among a group of buildings. The fire spread model proposed by Zhao [9] is adopted in this work. In the Zhao's model [9], the fire development in an individual building (i.e., ignition, flashover, fulldevelopment, and extinguishment) is simplified by defining the temperature and heat release rate of the burning building versus time. For the fire spread among a group of buildings, two main mechanisms that affect the fire spread: (1) thermal radiation, i.e., ejected flames and radiation through openings and heated exterior walls; and (2) thermal plume, i.e., plumes with high temperature. For a building that has not caught fire, if the received heat flux from the burning buildings is higher than its critical heat flux, it will then be ignited. Moreover, the influence of weather conditions, e.g., ambient temperature, humidity and rain, are also considered. The fire spread model was validated by comparing the simulation and real fire spread of the fire following the 1995 Kobe earthquake [9].

It should be noted, however, that the building seismic damage is not considered in the model in Zhao [9]. As a matter of fact, an earthquake may induce damage to walls, fire protection devices, gas systems, electrical systems, etc., which can further aggravate the fire spread. To date, only a limited number of existing fire spread models deals with building seismic damage, among which a representative model was proposed by Himoto et al. [3]. The principle of the work of Himoto et al. [3] is adopted in this work, i.e., assuming that the failure of the building exterior façade due to an earthquake will reduce the critical heat flux of ignition, as shown in Eq. (5).

$$
\dot{q}_{c r}=\varphi \dot{q}_{c r, H}+(1-\varphi) \dot{q}_{c r, L}
$$

where $\varphi$ is the failure ratio of the exterior façade, defined as the ratio of failed area to the total area of the exterior façade; $\dot{q}_{c r, H}, \dot{q}_{c r, L}$ are the critical heat flux when $\varphi=1$ and $\varphi=0$, respectively. The value of $\varphi$ and $\dot{q}_{c r, L}$ can be referred to [3] and [9], respectively.

$\alpha$ is defined as the critical heat flux reduction factor when the complete failure of the exterior façade occurs, as shown in Eq. (6).

$$
\alpha=\frac{\dot{q}_{c r, H}}{\dot{q}_{c r, L}}
$$

However, the value of $\alpha$ lacks sufficient references; hence, the influence of $\alpha$ on the fire spread simulation results will be further discussed in the case study of this work.

Note that Himoto et al. [3] did not provide further discussions on how to determine the building seismic damage; instead, the damage states of buildings were randomly assigned in their work. To overcome this limitation, Section 2.1 in this work provides a more reasonable prediction of building seismic damage simulation.

\section{CASE STUDY}

\subsection{Downtown Tangshan City}

Tangshan City is located in North China. On July 28th, 1976, the entire Tangshan City was ruined by an M7.8 earthquake. In that catastrophe, 2.85 million buildings collapsed, and 960,000 buildings were severely damaged. The earthquake did not cause fire disaster due to heavy rain. However, there were more than 30 fire ignitions in Tianjin City, $100 \mathrm{~km}$ away 
from Tangshan. To evaluate the potential FFE risk, a case study of FFE simulation for downtown Tangshan City was performed.

A total of 230,683 buildings were considered. The information of these buildings, including structural type, construction period, number of stories, etc., was provided by Tsinghua Tongheng Urban Planning and Design Institute, Beijing. The distribution of building construction periods and structural types are shown in Figure 2.

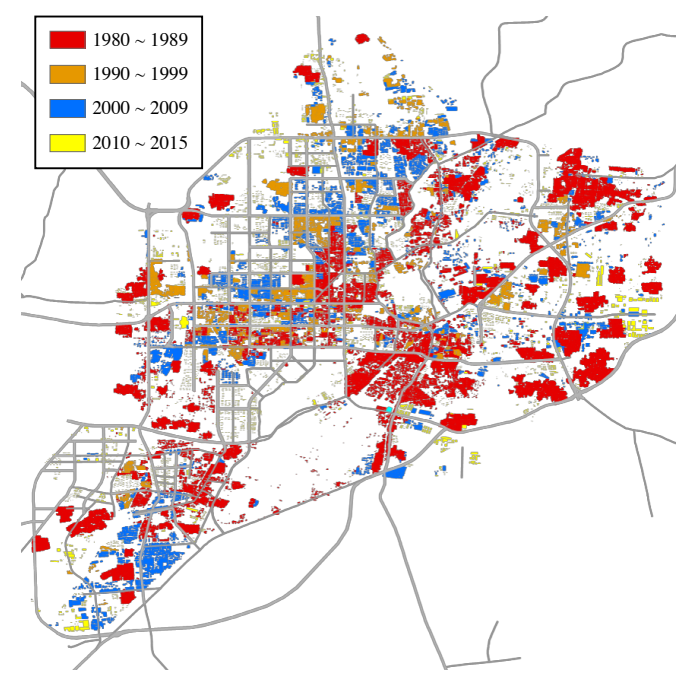

(a) construction periods

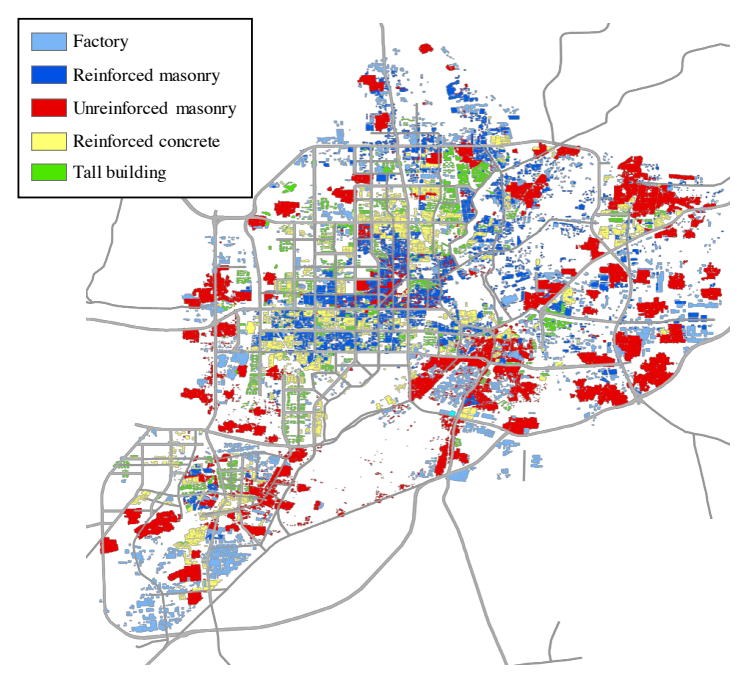

(b) building types

Figure 2: The information of buildings in downtown Tangshan City.

Due to the fact that the number of seismic observatories in China was very limited in 1976, the strong near-field ground motions of the main shock were not recorded. One of the ground motion record with relatively good quality was located in the observatory near Beijing Hotel. However, this observatory was $157 \mathrm{~km}$ away from the epicenter. After a long-distance propagation, the far-field record cannot reflect the characteristics of ground motions near the epicenter. As a result, in this simulation, 4 typical near-field records (hypocentral distance less than $10 \mathrm{~km}$ ) recommended in FEMA P695 report [10] were selected as the input ground motions. These ground motions were recorded during the M7.6 Chi-Chi earthquake, M7.5 Kacaeli earthquake, and M7.9 Denali earthquake. The magnitudes of these 3 earthquake events are close to that of Tangshan earthquake (M7.8). The normalized ground motion time-history curves are shown in Figure 3, where $\mathrm{H} 1$ and $\mathrm{H} 2$ stand for two horizontal components.

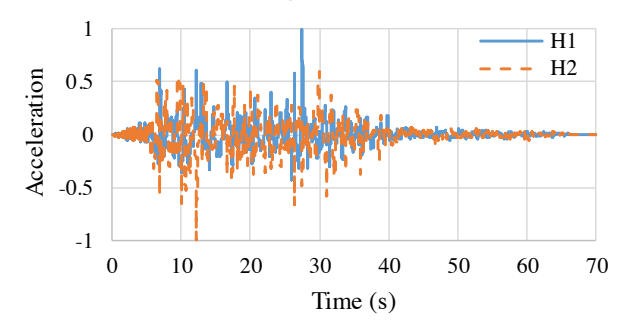

(a) CHICHI_TCU065

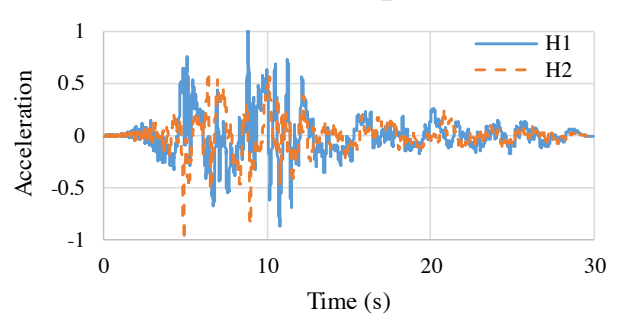

(b) KOCAEL_YPT 


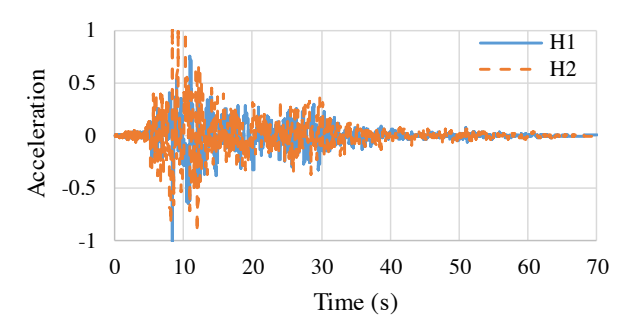

(c) CHICHI_TCU067

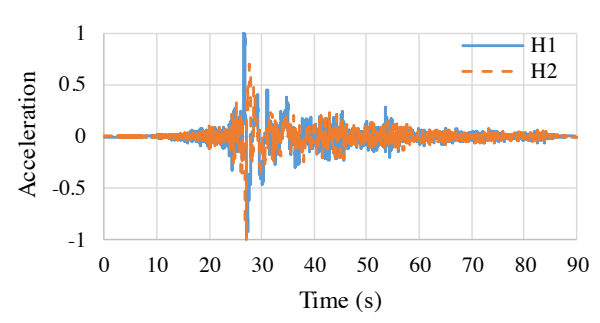

(d) DENALI_PS10

Figure 3: The four selected near-field ground motions (normalized).

Since the studied area is large, ground motion attenuation should be considered. In this study, the ground motion prediction equation (GMPE) suggested in the $5^{\text {th }}$ generation of seismic ground motion parameters zonation map of China [11] is adopted. The PGA distribution is calculated using the GMPE, shown in Figure 4.

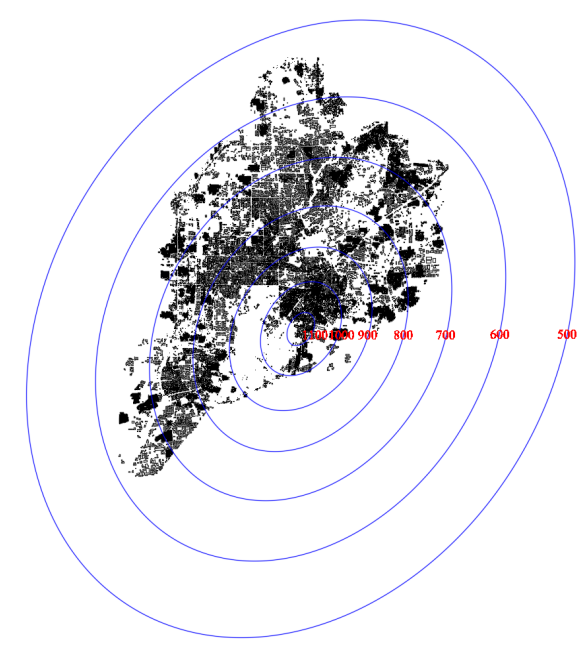

Figure 4: the PGA distribution calculated using the GMPE in [11]. (unit: $\mathrm{cm} / \mathrm{s}^{2}$ ).

\subsection{Fire ignition simulation}

The damage states of buildings can be obtained by performing the nonlinear THA for all the buildings in the case study region, using the 4 ground motions as input. Subsequently, the ignition risks $r$ under different ground motions and the mean ignition risks $r_{m}$ can be calculated using Eqs. (2) - (5). The number of ignited buildings $N=652$, according to Eq. (1). The top $N$ buildings with the highest $r_{m}$ are assumed to be the ignited buildings, as shown in Figure 5 . 


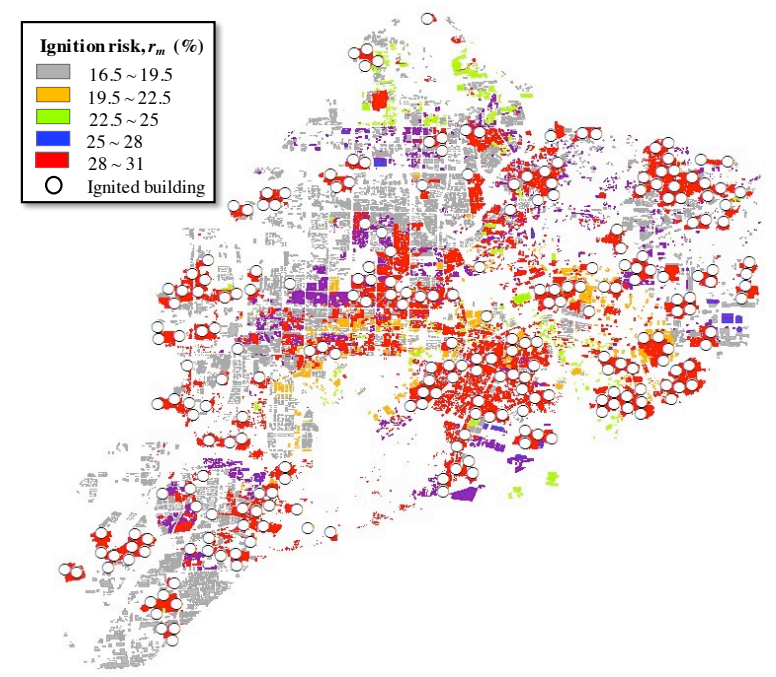

Figure 5: Ignition risks.

\subsection{Fire spread simulation}

Based on the 30-year statistics from 1971 to 2000, the weather conditions of Tangshan City in July are shown in Table 2 [12]. As a result, weather conditions of south-southeast (SSE) wind (wind speed $v=2.3 \mathrm{~m} / \mathrm{s}$ ), the lowest ambient temperature $T_{\text {low }}=21.7{ }^{\circ} \mathrm{C}$, the highest ambient temperature $T_{\text {high }}=30.2^{\circ} \mathrm{C}$, and the critical heat flux reduction factor $\alpha=0.4$ are selected as an example.

\begin{tabular}{llcl}
\hline $\begin{array}{l}\text { Average temperature } \\
\left({ }^{\circ} \mathrm{C}\right)\end{array}$ & $\begin{array}{l}\text { Average high } \\
\text { perature }\left({ }^{\circ} \mathrm{C}\right)\end{array}$ & $\begin{array}{c}\text { tem- Average low temper- } \\
\text { ature }\left({ }^{\circ} \mathrm{C}\right)\end{array}$ & $\begin{array}{l}\text { Average wind speed } \\
(\mathrm{m} / \mathrm{s})\end{array}$ \\
\hline 25.7 & 30.2 & 21.7 & 2.3 \\
\hline
\end{tabular}

Table 2: The weather conditions of Tangshan in July (based on the statistical data of 1971-2010) [12].

The fire spread simulation is performed after obtaining the ignition location. Figure 6 shows the damage of the central Tangshan City due to fire following CHICHI_TCU065 earthquake.

The curves of total footprint area burned subsequent to different ground motions are shown in Figure 7. The curves are close to each other, indicating that in this case the uncertainty of ground motions does not affect the fire spread results significantly. The fire spread is found to speed up at the beginning of the conflagration and slow down after $9 \mathrm{~h}$. After $40 \mathrm{~h}$, the fire is extinguished completely. When the suppression by the fire departments is not considered, the mean total footprint area burned is approximately $3.23 \mathrm{~km}^{2}$, accounting for $9.3 \%$ of the total footprint area of the buildings. 


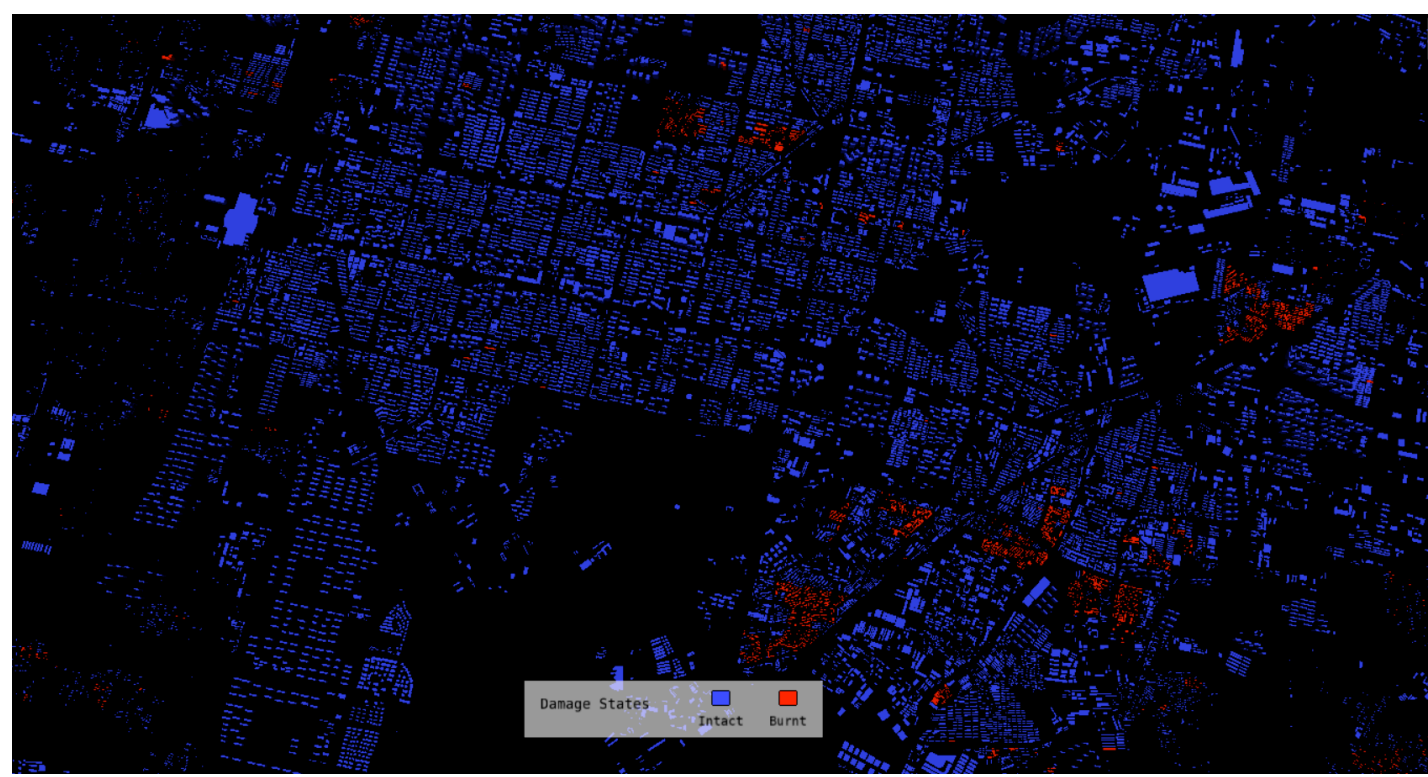

Figure 6: The damage of the central Tangshan City due to fire following CHICHI_TCU065 earthquake.

Due to the lack of sufficient data with respect to the value of critical heat flux reduction factor $\alpha$, the influence of this factor on the fire spread is discussed herein. When the weather conditions and ignition locations remain the same, the total footprint area burned (mean of the results of 4 ground motions) versus time for different values of $\alpha$ are as shown in Figure 8 . Note that $\alpha=1.0$ indicates that the influence of building seismic damage on fire spread is not considered. Figure 8 shows that a smaller $\alpha$ results in a greater aggravation of the fire spread due to the building damage. When $\alpha=0.4$, the total area burned (at $60 \mathrm{~h}$ ), considering building damage, increases by $32.5 \%$, compared to not considering building damage.

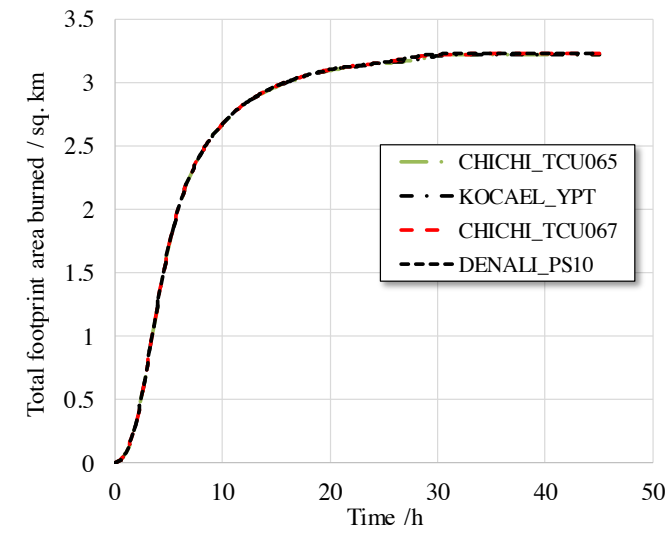

Figure 7: Total footprint area burned

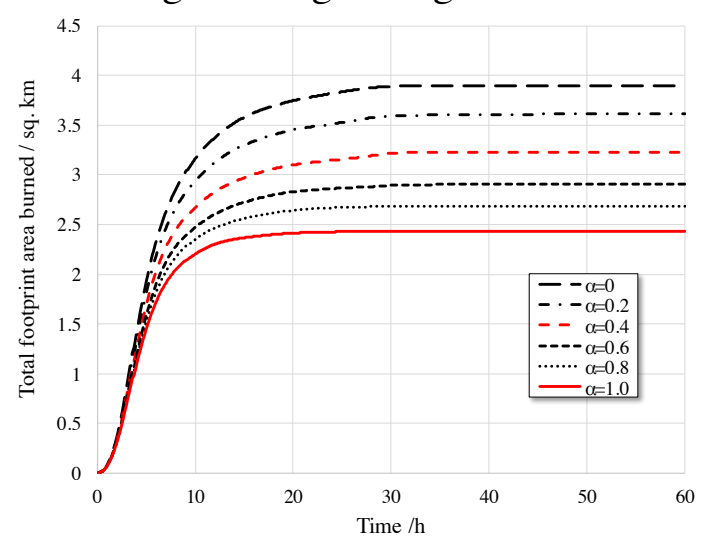

Figure 8: The influence of $\alpha$.

Wind is an important factor affecting fire spread. According to the available statistics, the wind directions of SSE, WNW, and ESE have a relatively high frequency [13], shown in Figure 9; while the average maximum wind speed in July and the maximum wind speed in July is $6 \mathrm{~m} / \mathrm{s}$ and $25 \mathrm{~m} / \mathrm{s}$, respectively [14]. When other conditions remain the same (when $\alpha=0.4$ ), the total footprint areas burned versus time for different wind speeds $v$ and different wind directions are shown in Figure 10. The case study shows that the ESE wind may result in a higher burned area than the direction of WNW and SSE. As for wind speed, when $v=2.3 \mathrm{~m} / \mathrm{s}$, the spread speed and the total burned areas are close to $v=0 \mathrm{~m} / \mathrm{s}$. When the wind speed is further increased, both the fire spread speed and the total burned area increase. 


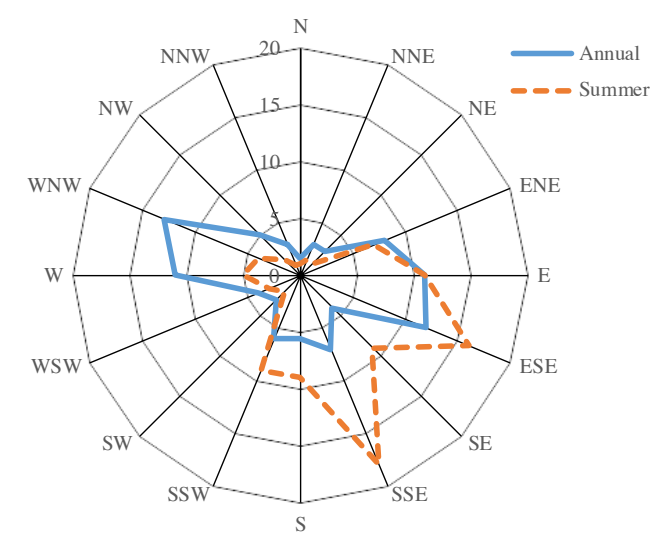

Figure 9: Wind rose plot of Tangshan City, based on the statistics from 1996-2005 [13].

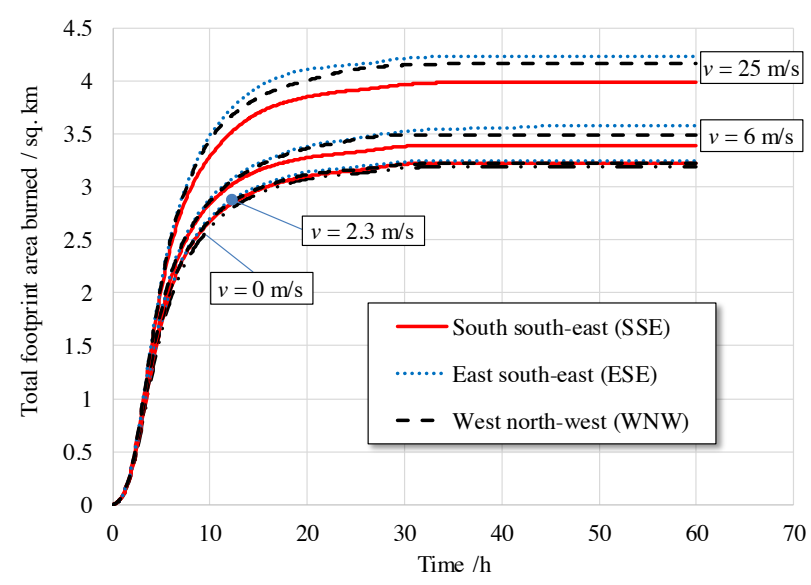

Figure 10: The influence of wind speed and wind direction.

\section{SUMMARY}

In this work, a framework for physics-based simulation considering the building seismic damage is proposed. A case study of the FFE simulation of downtown Tangshan City is performed. The conclusions can be drawn as follows:

(1) The seismic damage of regional buildings is simulated using the nonlinear MDOF building model and nonlinear THA, which is necessary for FFE simulation. Consequently, the influence of different ground motions and different building seismic resistances on the fire spread can be considered, which leads to a more rational and accurate FFE simulation.

(2) The seismic damage to an exterior façade will induce a larger burned area, which is not negligible.

\section{ACKNOWLEDGEMENTS}

The authors are grateful for the financial support from the National Key Technology R\&D Program (No. 2015BAK17B03) and the China Scholarship Council.

\section{REFERENCES}

[1] S. Mousavi, A. Bagchi, V.K. Kodur, Review of post-earthquake fire hazard to building structures. Canadian Journal of Civil Engineering, 35, 689-698, 2008.

[2] S. Lee, R. Davidson, N. Ohnishi, C. Scawthorn, Fire following earthquake-Reviewing the state-of-the-art of modeling. Earthquake Spectra, 24, 933-967, 2008.

[3] K. Himoto, K. Mukaibo, Y. Akimoto, R. Kuroda, A. Hokugo, T. Tanaka, A PhysicsBased Model for Post-Earthquake Fire Spread Considering Damage to Building Components Caused by Seismic Motion and Heating by Fire. Earthquake Spectra, 29, 793-816, 2013.

[4] X.Z. Lu, B. Han, M. Hori, C. Xiong, Z. Xu, A coarse-grained parallel approach for seismic damage simulations of urban areas based on refined models and GPU/CPU cooperative computing. Advances in Engineering Software, 70, 90-103, 2014. 
[5] C. Xiong, X.Z. Lu, H. Guan, Z. Xu, A nonlinear computational model for regional seismic simulation of tall buildings. Bulletin of Earthquake Engineering, 14, 1047-1069, 2016.

[6] C. Xiong, X.Z. Lu, X.C. Lin, Parameter determination and damage assessment for THAbased regional seismic damage prediction of multi-story buildings. Journal of Earthquake Engineering, 2016.

[7] A.Z. Ren, X.Y. Xie, The simulation of post-earthquake fire-prone area based on GIS. Journal of Fire Sciences, 22, 421-439, 2004.

[8] S.J. Zhao, Study on Risk Assessment and Simulation of Urban Post-earthquake Fire Based on GIS. Beijing, 2006.

[9] S.J. Zhao, GisFFE - an integrated software system for the dynamic simulation of fires following an earthquake based on GIS. Fire Safety Journal, 45, 83-97, 2010.

[10] FEMA. P695 - Quantification of building seismic performance factors. Federal Emergency Management Agency, Washington, D.C., 2009.

[11] GB. Seismic ground motion parameters zonation map of China. GB 18306-2015, Beijing, 2015.

[12] China Weather, Basic weather conditions of Tangshan, China (based on statistics of 1971-2000). http://www.weather.com.cn/cityintro/101090501.shtml, 2017.

[13] L. Yin, The relationship between wind character and industrial areas selection in Tangshan. Journal of Tangshan Teachers College, 36, 144-146, 2014.

[14] Q. Long, Y.J. Meng, F. Wang, Y.X. Zheng, X.M. Fu, Primary research about wind characteristics of Tangshan Caofeidian waters. Marine Forecasts, 30, 32-37, 2013. 